\title{
Biochemical formation of anthocyanins in silk tissue of Zea mays
}

\author{
Heidrun Halbwirth ${ }^{\mathrm{a}}$, Stefan Martens ${ }^{\mathrm{b}}$, Udo Wienand ${ }^{\mathrm{c}}$, Gert Forkmann ${ }^{\mathrm{b}}$, Karl Stich ${ }^{\mathrm{a} *}$ \\ a Institute for Technical BioScience, Technical University of Vienna, Getreidemarkt 9/173, A-1060 Vienna, Austria \\ ${ }^{\mathrm{b}}$ Chair of Floriculture Crops and Horticultural Plant Breeding, TUM Weihenstephan, Am Hochanger 4, D-85350 Freising, Germany \\ ${ }^{\mathrm{c}}$ Institut für Allgemeine Botanik, Universität Hamburg, D-22609 Hamburg, Germany
}

Received 19 August 2002; received in revised form 12 December 2002; accepted 12 December 2002

\begin{abstract}
Two types of anthocyanins are formed in tissues of Zea mays (maize), the common 3-hydroxyanthocyanins and the rare 3deoxyanthocyanins. Their formation is generally controlled by independent regulatory genes. Whereas the formation of 3hydroxyanthocyanins is well established, the enzymes involved in the biosynthesis of the 3-deoxyanthocyanins remained unclear for a long time. In order to elucidate the key reaction involved, the reduction of flavanones to flavan 4-ols, dihydroflavonol 4-reductase (DFR) and flavanone 4-reductase (FNR) activities were investigated using enzyme preparations from silks of different maize lines as well as from transgenic petunia and yeast, respectively, expressing the A1 gene of maize. This gene is known to encode DFR. DFR and FNR activities could not be separated by biochemical investigations and the use of different enzyme inhibitors. In maize genotypes with recessive alleles (a1a1) of the A1 gene, neither DFR nor FNR activity was present. Moreover, heterologous expression of A1 in petunia and yeast has shown that the gene encodes for a reductase, which is able to convert both dihydroflavonols (DFR activity) and flavanones (FNR activity) to flavan 3,4-diols and flavan 4-ols, respectively. Thus, DFR and FNR activities are provided by one and the same enzyme with a broad substrate acceptance, which even includes the 5deoxydihydroflavonols. Further studies suggested that the anthocyanin type formed in the silks essentially depends on the strength of flavanone 3-hydroxylase activity.
\end{abstract}

(C) 2003 Elsevier Science Ireland Ltd. All rights reserved.

Keywords: Zea mays (maize); Flavonoids; 3-Deoxyflavonoids; Dihydroflavonol 4-reductase; Flavanone 4-reductase; Anthocyanins

\section{Introduction}

Anthocyanins are a major class of flavonoids showing bright colouration ranging from blue to orange. Two different types of anthocyanins can be formed in maize and their formation is controlled by several independent regulatory genes [1-3]. While the gene $R$ effects the formation of the common 3-hydroxyflavonoids [4], the gene $P$ controls the biosynthesis of 3-deoxyflavonoids and related phlobaphenes [5]. 3-Hydroxyanthocyanins can be formed in almost every tissue of maize plants, whereas the biosynthesis of the 3-deoxyanthocyanins is restricted to the pericarp and the cicatricial tissue of the pistillate flower, which is commonly called silk. In contrast to the common 3-hydroxyanthocyanins which

\footnotetext{
* Corresponding author. Tel.: +43-1-5880117320; fax: +43-15880117399 .

E-mail address: karl.stich+e166@tuwien.ac.at (K. Stich).
}

are widely spread in nature, the rare 3-deoxyanthocyanins lacking a hydroxyl group in position 3 can be found only in a few plant species. Apart from tissues of Zea mays [1], they were reported to be present as flower pigments in Gesneriaceae [6,7]. Moreover, in Sorghum species [8] 3-deoxyanthocyanins play an important role as phytoalexins. Whereas the biosynthesis of the common anthocyanins has been extensively investigated in various plants [9-11], the formation of the rare 3deoxyanthocyanins has long remained open. First studies on their biosynthesis were carried out with enzyme extracts from flowers of Sinningia cardinalis [12] and Columnea hybrida [13]. A new enzyme activity was demonstrated which was able to catalyze the reduction of flavanones (naringenin and eriodictyol) to flavan 4-ols (apiforol and luteoforol), and thus provided the immediate precursors of the 3-deoxyanthocyanidins (apigeninidin and luteolinidin). The enzyme was called flavanone 4-reductase (FNR). 


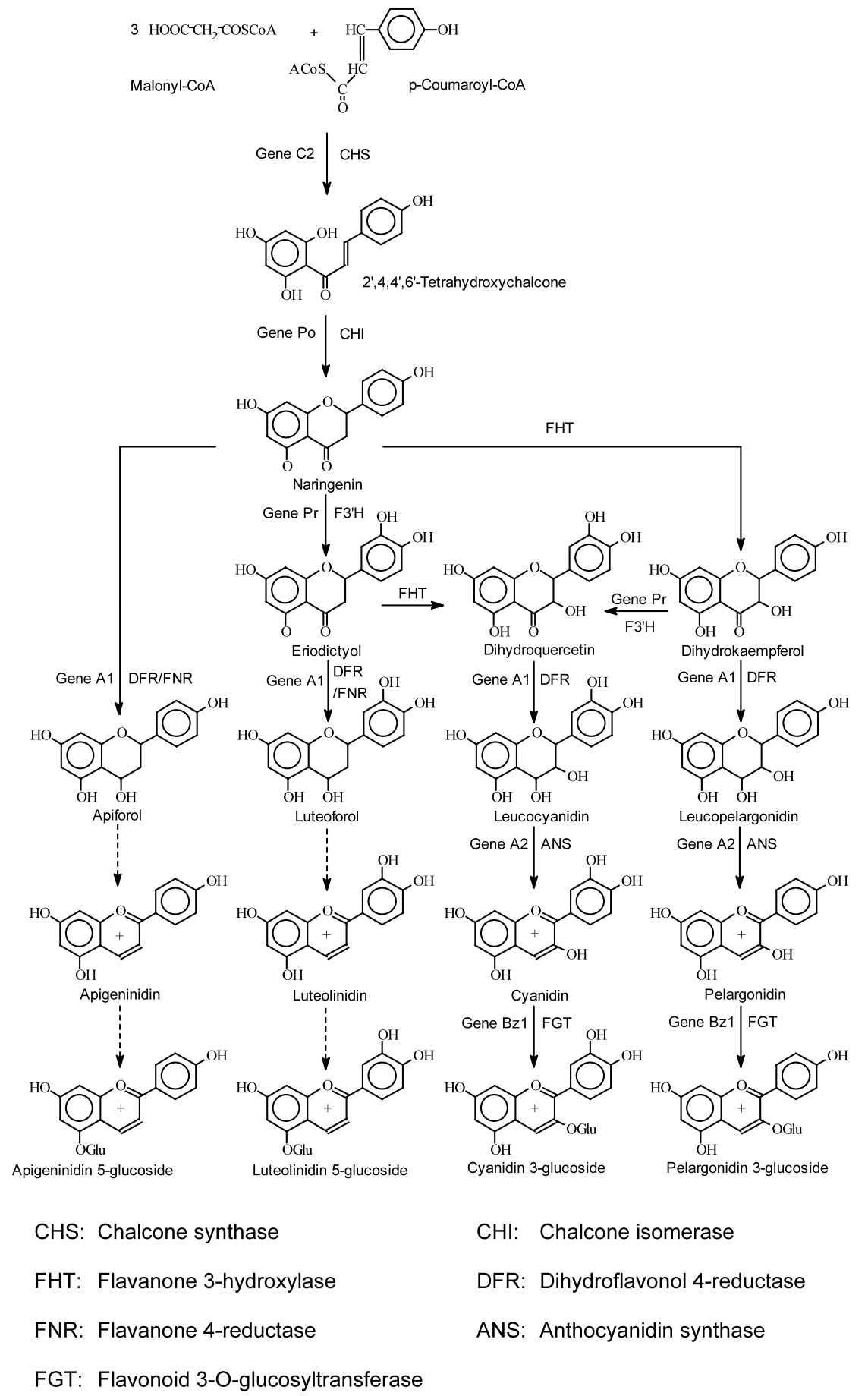

Fig. 1. Anthocyanin biosynthesis in maize: summary of biochemical, genetic and molecular biological knowledge.

The general pathway to anthocyanins is shown in Fig. 1. Dihydroflavonol 4-reductase (DFR) (EC number 1.1.1.219) is one of the key enzymes of the pathway leading to the formation of 3-hydroxyanthocyanins. The enzyme catalyzes the stereospecific reduction of $(+)-$ $(2 R, 3 R)$-dihydroflavonols to the respective $(2 R, 3 S$, $4 S$ )-flavan-2,3-trans-3,4-cis-diols, which are commonly called leucoanthocyanidins. DFR enzymes often show distinct substrate specificity with respect to dihydro- flavonols (dihydrokaempferol, dihydroquercetin, dihydromyricetin) [9-11] and thus, have strong influence on the type of anthocyanidin (pelargonidin, cyanidin, delphinidin) formed in the plant tissues. DFR enzymes from plants, which do not naturally form 3-deoxyflavonoids in their tissues showed divergent substrate specificities with respect to flavanones. Moreover, it remained an open question, whether the reduction of flavanones is catalyzed by DFR or by FNR as a novel independent 
enzyme activity. Enzyme preparations from $S$. cardinalis flowers catalyzed the reduction of both flavanones to flavan 4-ols and dihydroflavonols to flavan 3,4-diols [12] even when the preparations were made from tissue which contained exclusively 3-deoxyanthocyanins. On the other hand, DFR preparations from Matthiola [14] and Dianthus [15], which do not naturally form 3deoxyflavonoids, did only convert dihydroflavonols, whereas the purified enzyme from Dahlia [16] catalyzed both the reduction of dihydroflavonols and flavanones. But the latter result may only be valid for the purified enzyme, because the reduction of flavanones is not in agreement with the exclusive presence of 3-hydroxyflavonoids in Dahlia.

During the past years the anthocyanin pathway in Zea mays (maize) has been regarded as excellent model system for genetic and molecular studies due to the tissue-specific expression of anthocyanins taking advantage of the easy perceptibility of mutations in the genome by changes in the tissue colour. More than 20 different genes are known to have influence on the biosynthesis of flavonoids including anthocyanins (Fig. 1 ), and many regulatory and structural genes involved turned out to be present in two copies. Numerous reports on various aspects of flavonoid biosynthesis in maize are available, the vast majority of them based on genetic or molecular biological investigations including transformation of structural or regulatory maize genes into other plants and analyzing the resulting changes in their flavonoid spectrum. However, only a few biochemical studies on the enzyme activities of the flavonoid pathway in maize have been published so far (FGT: [17-19]; F3'H: [20,21]).

The A1 gene has been identified by genetic, molecular biological and biochemical means as structural gene of the DFR [22-24] in maize. There is strong chemicogenetic [2] but not yet biochemical evidence that the A1 gene also concerns the formation of flavan 4-ols. Biochemical studies on a defined maize plant material and on transgenic Petunia and yeast expressing the A1 gene should unequivocally reveal whether or not the enzyme encoded by A1 expresses both DFR and FNR activity and finally answer the question in which way 3hydroxyanthocyanins and 3-deoxyanthocyanins are formed in maize.

\section{Material and methods}

\subsection{Plant material}

For the investigations the following maize lines were used: Peterson Ac 1355 A-D (all: sm, $\mathrm{P}^{\mathrm{RR}}$; provided by P.A. Peterson, University Ames), a1-line (a1/W22; provided by U. Wienand, University Hamburg) and the commercially available cultivar 'Pirat' (Südwest Saat,
Germany). Silk tissues were harvested during summer 1995 and 2001, frozen with liquid nitrogen and stored at $-80{ }^{\circ} \mathrm{C}$. For the investigations with Petunia hybrida the mutant line RL01 lacking $\mathrm{F}^{\prime} \mathrm{H}$ and $\mathrm{F}^{\prime}{ }^{\prime}{ }^{\prime} \mathrm{H}$ activity and accumulating DHK due to the distinct substrate specificity of petunia DFR [25] and a respective transgenic line expressing the Al gene of maize were used [26]. Both lines were from our plant collection.

\subsection{Chemicals}

$\left[2-{ }^{14} \mathrm{C}\right]$ Malonyl-coenzyme A $(55 \mathrm{mCi} / \mathrm{mmol})$ was purchased from Amersham International (UK). $\left[{ }^{14} \mathrm{C}\right] \mathrm{Nar}-$ ingenin (NAR) was prepared as described $[27,28]$ using a heterologously expressed chalcone synthase cDNA clone (J. Schroeder, University of Freiburg, Germany) in $E$. coli and a crude enzyme preparation of dahlia containing chalcone isomerase activity. $\left[{ }^{14} \mathrm{C}\right]$ Eriodictyol (ERI) was synthesised from $\left[{ }^{14}\right.$ C]NAR [29] using flavonoid 3'-hydroxylase (F3'H) activity of microsomal preparations from Tagetes erecta. $\left[{ }^{14} \mathrm{C}\right]$ Dihydrokaempferol was prepared from $\left[{ }^{14} \mathrm{C}\right] \mathrm{NAR}[29]$ with heterologously expressed flavanone 3-hydroxylase (FHT) (R. Lukacin, University of Marburg, Germany) in E. coli and used for preparation of $\left[{ }^{14} \mathrm{C}\right]$ dihydroquercetin with microsomal preparations from Tagetes erecta according to Stotz et al. [29].

\subsection{Enzyme assays}

DFR/FNR assays with enzyme preparations from silks were carried out according to [12]. The organic phases were applied to a precoated cellulose plate (Merck, Germany) and chromatographed with the following solvent systems: (1) chloroform:acetic acid: water (10:9:1); (2) 30\% HAc; (3) $n$-butanol saturated with $0.01 \mathrm{M}$ potassium-phosphate buffer $\mathrm{pH} 6.8$; (4) $n$ butanol:acetic acid:water (6:1:2). Radioactivity was detected and quantified using a TLC Linear Analyzer (Berthold, Germany). FHT assays were carried out as previously described [29]. Protein content was determined by a modified Lowry procedure [30] using crystalline BSA as a standard.

\subsection{Enzyme kinetics}

Kinetic data were calculated from Lineweaver-Burk plots. Determination of the apparent Michaelis constant $\left(K_{\mathrm{m}}\right)$ and maximal reaction velocity $\left(V_{\max }\right)$ were performed with a fixed concentration of $5 \mathrm{mM}$ NADPH.

\subsection{Isolation, cloning and heterologous expression of maize $c D N A$}

The cDNA clone A1, encoding DFR of Zea mays (Acc. no. X05068), was amplified by PCR from plasmid 
pALCc92 [22] using forward primer 5'-GATAATGGAGAGAGGTGCCGGT-3' and the reverse primer 5'GCCGGGTGATTGTTGCTTAAGC-3'. Amplification was carried out for 30 cycles at the following conditions: $95{ }^{\circ} \mathrm{C} / \mathrm{min}, 55{ }^{\circ} \mathrm{C} / \mathrm{min}, 72{ }^{\circ} \mathrm{C} / 2 \mathrm{~min}$ using High Fidelity DNA Polymerase (Roche, Germany) The obtained PCR fragment of approximately $970 \mathrm{bp}$ was directly cloned into $\mathrm{pYES} 2.1 / \mathrm{V} 5$-His TOPO T/A cloning vector (Invitrogen, The Netherlands). After checking the orientation of the insert by restriction analysis using internal Sma I and vector Xba I cutting site, and confirmation by sequencing, both sense and antisense constructs were transformed in yeast strain INV Sc1 for overexpression. Overexpression and isolation of the protein was done according to [31].

\section{Results}

\subsection{Chemical studies}

Chromatographic and spectrophotometric analyses of the anthocyanins present in the silks of four lines with recessive sm-alleles ('sm-lines', Section 2) identified two lines containing exclusively 3-deoxyanthocyanins (Peterson Ac 1355 B and Peterson Ac 1355 D) and two lines containing both 3-deoxyanthocyanins and 3-hydroxyanthocyanins (Peterson Ac $1355 \mathrm{~A}$ and Peterson Ac $1355 \mathrm{C})$. Moreover, the commercially available cultivar 'Pirat' was found to accumulate exclusively 3-hydroxyanthocyanins. No anthocyanins are formed in the silks of the line with the recessive a1-allels (a1a1).

\subsection{DFR/FNR activity}

Incubation of DHK or DHQ with enzyme preparations from silks of maize cv. 'Pirat' or the four 'sm-lines' in the presence of NADPH led to the formation of the flavan 3,4-diols, leucopelargonidin and leucocyanidin, respectively. Incubation of ERI under the same conditions also led to the formation of one single product, which was identified as the flavan 4-ol, luteoforol, in four different solvent systems. NAR was also accepted as substrate leading to the formation of the flavan 4-ol, apiforol, but the conversion rate was very low (below $3 \%$ ). Besides flavanones and dihydroflavonols the 5deoxydihydroflavonols garbanzol (5-deoxydihydrokaempferol) and dihydrofisetin (5-deoxydihydroquercetin) were also accepted as substrates by the enzyme preparations.

The DFR and FNR activities were further characterized from silk extracts of both the cv. 'Pirat' and the 'smlines'. Neither the biochemical parameter measured (Table 1) nor the effects of various inhibitors (Table 2) on DFR and FNR activities, respectively, did provide clear evidence for the presence of two different enzymes in the silk extracts. Further investigations were performed using genotypes with dominant and recessive alleles, respectively, of the A1 gene encoding DFR. Both DFR and FNR activity could easily be demonstrated in the line with the dominant A1 allele, whereas in the line with recessive alleles (a1a1), neither DFR nor FNR activity was detectable.

Besides enzyme preparations from different maize genotypes, we also used enzyme extracts from two different sources with a heterologous expressed A1 gene. As expected, the petunia DFR extracted from flowers of the original line RL01 did convert DHQ to leucocyanidin (Fig. 2A), but the flavanone eriodictyol was not accepted as substrate (Fig. 2 B). In contrast, enzyme preparations from flowers of a transgenic RL01 line harboring the A1 gene [26] clearly showed DFR activity with DHK, which is not used as substrate by the Petunia own DFR [25], proving expression of the A1 gene (Fig. 2C). In addition, FNR activity was present catalyzing reduction of eriodictyol to luteoforol (Fig. 2D). Moreover, a cDNA clone was heterologously expressed in yeast according to Martens et al. [31]. Enzyme preparations from yeast expressing the A1 gene showed DFR and FNR activity converting DHK and DHQ to the respective flavan 3,4-diols as well as eriodictyol to luteoforol (data not shown). The enzyme extracts with the heterologous expressed A1 gene converted DHK, DHQ and ERI to a similar extent as observed in extracts of the tested maize lines. NAR was again barely accepted as substrate. As expected, neither DFR nor FNR activity was present in enzyme extracts from yeast with the antisense construct.

\subsection{FHT activity}

Incubation of NAR or ERI with enzyme preparations from silks of cv. 'Pirat' accumulating exclusively 3hydroxyanthocyanins in the presence of 2-oxoglutarate and $\mathrm{Fe}^{2+}$ led to the formation of the respective dihydroflavonol to a high extent (more than 90\% conversion rate). Under the same conditions enzyme preparations from the two 'sm-lines' containing 3hydroxyanthocyanins and 3-deoxyanthocyanins were able to convert NAR and eriodictyol to the respective dihydroflavonols only to a considerably lower extent, and no FHT activity could be observed in enzyme preparations from the two 'sm-lines' containing exclusively 3-deoxyanthocyanins (Peterson Ac 1355 B and Peterson Ac 1355 D).

\section{Discussion}

The A1 gene has been identified as the structural gene of DFR and chemico-genetic results prove that it is also involved in the formation of the flavan 4-ols. But 
Table 1

Enzymatic features of DFR activity and FNR activity

\begin{tabular}{|c|c|c|c|c|}
\hline & \multicolumn{2}{|l|}{ cv. 'Pirat' } & \multicolumn{2}{|l|}{ Line 'sm' } \\
\hline & DFR-activity & FNR-activity & DFR-activity & FNR-activity \\
\hline Substrates accepted & DHK, DHQ, Gar, DHF & NAR, ERI & DHK, DHQ, Gar, DHF & NAR, ERI \\
\hline Cofactors & 5 mM NADPH & $5 \mathrm{mM}$ NADPH & 5 mM NADPH & $5 \mathrm{mM}$ NADPH \\
\hline rel. act. (\%) with NADH & 58 & 60 & 60 & 15 \\
\hline pH-optimum & $6.6(\mathrm{DHQ})$ & $5.8(\mathrm{ERI})$ & 6.8 (DHQ) & $5.8(\mathrm{ERI})$ \\
\hline Optimal temperature & $30{ }^{\circ} \mathrm{C}$ & $25^{\circ} \mathrm{C}$ & $30{ }^{\circ} \mathrm{C}$ & $25^{\circ} \mathrm{C}$ \\
\hline Time linearity & up to $15 \mathrm{~min}$ & up to $15 \mathrm{~min}$ & up to $15 \mathrm{~min}$ & up to $30 \mathrm{~min}$ \\
\hline Temperature stability & up to $40{ }^{\circ} \mathrm{C}$ & up to $30{ }^{\circ} \mathrm{C}$ & up to $40{ }^{\circ} \mathrm{C}$ & up to $30{ }^{\circ} \mathrm{C}$ \\
\hline Protein linearity & up to $2 \mu \mathrm{g}$ protein & up to $8 \mu \mathrm{g}$ protein & up to $2 \mu \mathrm{g}$ protein & up to $5.5 \mu \mathrm{g}$ protein \\
\hline$K_{\mathrm{m}}(\mu \mathrm{M})$ & 9.5 & 6.4 & 23 & 17 \\
\hline$V_{\max }(\mu \mathrm{kat} / \mathrm{kg})$ & 78 (DHQ) & 15 & 120 & 48 \\
\hline$V_{\max } / K_{\mathrm{m}}$ & 8 & 2.5 & 5 & 3 \\
\hline
\end{tabular}

Assays for DFR activity and FNR activity were optimised using enzyme preparations from two different varieties of $Z$. mays. Abbreviations: DHK. dihydrokaempferol; DHQ, dihydroquercetin; DHF, dihydrofisetin; Gar, garbanzol; NAR, naringenin; ERI, eriodictyol; rel. act., activity with $5 \mathrm{mM}$ NADH compared to activity with $5 \mathrm{mM}$ NADPH.

biochemical data are not yet gained. Therefore, we investigated the question, whether or not the DFR and FNR reaction is catalyzed by one and the same enzyme. The biochemical data and the results with different enzyme inhibitors revealed no essential differences between DFR and FNR activities. The pH-optimum for a reaction observed in vitro is often strongly dependent from the respective substrate used $[9,10,16]$ and the slight differences in temperature optimum and temperature stability did not allow a definite conclusion. The fact, however, that both DFR and FNR activity were controlled by the A1 gene provided strong evidence that one and the same enzyme might be responsible for
DFR and FNR activity rather than two different enzymes. Final proof was established by using enzyme extracts from transgenic petunia and yeast with a heterologously expressed A1 gene. Because the petunia DFR accepts DHQ and DHM but not DHK as substrate, no pelargonidin (Pg) derivatives are naturally formed in the flowers [25]. Introduction of the maize A1 gene encoding a DFR which is able to reduce DHK to $\mathrm{LPg}$ in a suitable petunia target line resulted in the creation of the Pg-type of petunia [26]. We used this plant material and found that in flower extracts of the untransformed target line only DFR activity was present. Thus, the petunia DFR possesses not only a

Table 2

Influence of inhibitors on DFR activity and FNR activity

\begin{tabular}{|c|c|c|c|c|c|}
\hline \multirow[t]{2}{*}{ Inhibitor } & \multirow[t]{2}{*}{ Conc. (mM) } & \multicolumn{2}{|l|}{ cv. 'Pirat' } & \multicolumn{2}{|l|}{ Line 'sm' } \\
\hline & & DFR (\%rel.) & FNR (\%rel.) & DFR (\%rel.) & FNR (\%rel.) \\
\hline None & - & 100 & 100 & 100 & 100 \\
\hline \multirow[t]{2}{*}{$\mathrm{KCN}$} & 1 & 100 & 100 & 100 & 100 \\
\hline & 5 & 100 & 100 & 100 & 100 \\
\hline \multirow[t]{2}{*}{ EDTA } & 1 & 97 & 102 & 100 & 95 \\
\hline & 5 & 97 & 99 & 97 & 99 \\
\hline \multirow[t]{2}{*}{ p-Hydroxymercuribenzoate } & 1 & 0 & 0 & 0 & 0 \\
\hline & 5 & 0 & 0 & 0 & 0 \\
\hline \multirow[t]{2}{*}{ 2, 2'-Bipyridyl } & 1 & 88 & 95 & 97 & 95 \\
\hline & 5 & 89 & 93 & 96 & 89 \\
\hline \multirow[t]{2}{*}{ 8-Hydroxyquinoline } & 1 & 112 & 111 & 93 & 95 \\
\hline & 5 & 112 & 115 & 88 & 92 \\
\hline \multirow[t]{2}{*}{ 1,10-Phenanthroline } & 1 & 88 & 70 & 76 & 91 \\
\hline & 5 & 53 & 32 & 46 & 54 \\
\hline \multirow[t]{2}{*}{ Potassium azide } & 1 & 110 & 110 & 110 & 108 \\
\hline & 5 & 111 & 112 & 111 & 109 \\
\hline
\end{tabular}

Enzyme activities were measured in the presence of various potential inhibitors using enzyme preparations from two different varieties of $Z$. mays. Relative activity (\%rel.) was calculated compared to a control. Data represent an average of three independent experiments. Abbreviation: ERI, eriodictyol; DHK, dihydrokaempferol; Lpg, leucopelargonidin; Lcy, leucocyanidin; CHS, chalcone synthase; CHI, chalcone isomerase; FHT, flavanone 3-hydroxylase; DFR, dihydroflavonol 4-reductase; FNR, flavanone 4-reductase; ANS, anthocyanidin synthase; FGT, flavonoid 3-Oglucosyltransferase. 

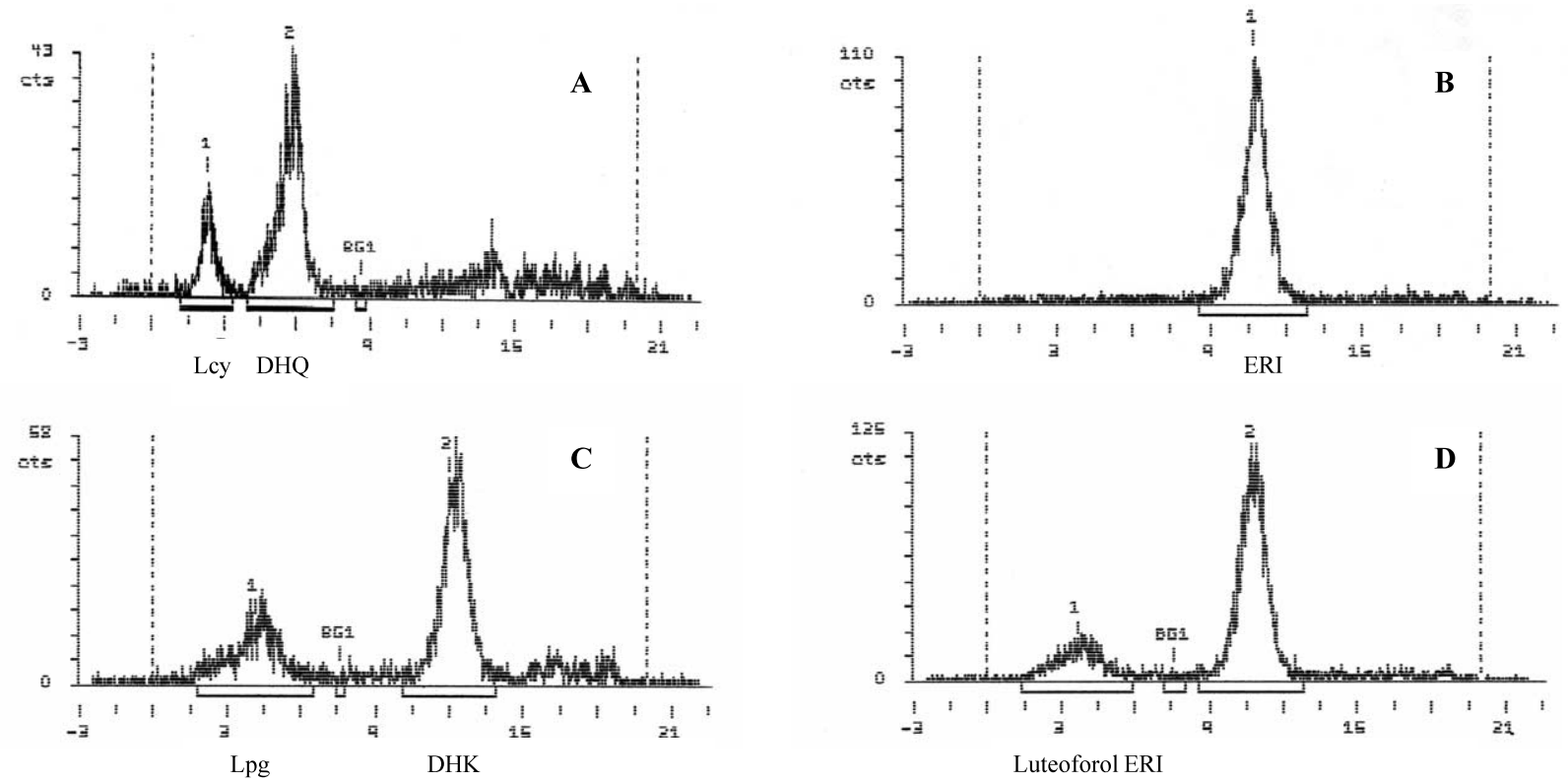

Fig. 2. Radioscan of TLC on cellulose with solvent system CAW (chloroform/acetic acid/water $=50 / 45 / 5$ ) from incubation of enzyme preparations from Petunia hybrida (A, B: original line RL01, C, D: trangenic line) in the presence of NADPH with DHQ (A) or DHK (C) and ERI (B, D) as substrates.

distinct substrate specificity with regard to dihydroflavonols but does also not accept flavanones as substrates. In contrast, in the transgenic petunia plants harboring the A1 gene, DFR and FNR activity was present, as observed in enzyme preparations from maize tissue with the active A1 allele. The additional presence of FNR activity can only be explained by the heterologous expression of the A1 gene. Very recently, the successful expression of DFR cDNA clones in yeast and plant protoplasts leading for the first time to active DFR enzymes was reported [31]. Thus, we also used the yeast system for the heterologous expression of the A1 gene. DFR activity was only found in enzyme extracts prepared from yeast harboring the A1 gene and, in addition, FNR activity was present. The results with petunia and yeast provided unequivocal confirmation of the fact that the A1 gene encodes a reductase with DFR and FNR activity (Figs. 1 and 2).

The kinetic studies clearly identified dihydroflavonols to be the preferred substrates, since the ratio $V_{\max } / K_{\mathrm{m}}$, a key figure for substrate specificity, was clearly higher for DHQ than for eriodictyol. Thus, it is obvious that A1 encodes for a DFR with additional FNR activity. Nevertheless, the rather high $V_{\max } / K_{\mathrm{m}}$-value (3.0) for eriodictyol indicates this compound to be a very good substrate also under natural conditions.

NAR turned out to be a poor substrate. But this fact does not mean that maize tissues are generally not able to form anthocyanins of the apigeninidin-type. In the absence of FHT and F3'H activity, NAR may be accumulated and exclusively available as substrate for the reduction by FNR. Thus, over a long period, modest amounts of apiforol could be formed, which is the immediate precursor for apigeninidin.

The maize reductase seems to express a very broad substrate acceptance. Thus, the enzyme was also able to convert the 5-deoxydihydroflavonols garbanzol and dihydrofisetin to a very high extent to the respective leucoanthocyanidins, although 5-deoxydihydroflavonols or other 5-deoxyflavonoids are naturally not formed in maize tissues.

Besides DFR/FNR activities FHT activity was investigated in the different lines. There was a clear correlation observed between the formation of 3-hydroxyanthocyanins and/or 3-deoxyanthocyanins and FHT activity. But the lines tested are apparently in a widelyvarying genetic background, and hence variation at a number of loci may have affected these results. The differences in the accumulation of the two anthocyanin types may be explained by the fact that FHT and FNR compete for flavanones as common substrates. In the presence of high FHT activity (cv. 'Pirat'), flavanones are rapidly hydroxylated to dihydroflavonols, which are the preferred substrates for DFR, and subsequently converted to the 3-hydroxyanthocyanins, whereas in the two 'sm-lines' lacking FHT activity, the accumulating flavanones can be used by the FNR without competition. Therefore, exclusively 3-deoxyanthocyanins are formed in the respective silks. Moreover, the low FHT activity observed in two further 'sm-lines' is in agreement with the presence of a mixture of both anthocyanin types found in this lines. In this case, both the FHT and the FNR will use the available flavanones as substrates for their respective reactions. Thus, in the investigated 
plant material the strength of the FHT activity rather than the DFR/FNR activity seems to be decisive for the formation of 3-hydroxyanthocyanins and/or 3-deoxyanthocyanins in maize silks.

\section{Acknowledgements}

These investigations were supported by the Fonds zur Förderung wissenschaftlicher Forschung (FWF) Austria (Project number: P 10 280-CHE). We thank Eva Meggeneder for critically reading the manuscript.

\section{References}

[1] E.D. Styles, O.C. Ceska, Genetic control of 3-hydroxy- and 3deoxyflavonoids in Zea mays, Phytochemistry 14 (1975) 413-415.

[2] E.D. Styles, O.C. Ceska, The genetic control of flavonoid synthesis in maize, Can. J. Genet. Cytol. 19 (1977) 289-302.

[3] H.K. Dooner, T.P. Robbins, R.A. Jorgensen, Genetic and developmental control of anthocyanin biosynthesis, Ann. Rev. Genet. 25 (1991) 173-199.

[4] R.L. Larson, Genetics, precursors and enzymes in flavonoid biosynthesis in maize, in: D.E. Styles, G.A. Gavazzi, M.L. Racchi (Eds.), The Genetics of Flavonoids, Edizioni Unicopli, Milan, 1989, pp. 71-76.

[5] E. Grotewold, B.J. Drummond, B. Bowen, T. Peterson, The mybhomologous $P$ gene controls phlobaphene pigmentation in maize floral organs by directly activating a flavonoid biosynthetic gene subset, Cell 76 (1994) 543-553.

[6] J.B. Harborne, Comparative biochemistry of flavonoids. II. 3Deoxyanthocyanins and their systematic distribution in ferns and gesneriads, Phytochemistry 5 (1966) 589-600.

[7] J.B. Harborne, Comparative biochemistry of the flavonoids VI. Flavonoid patterns in the Bignoniaceae and the Gesneriaceae, Phytochemistry 6 (1967) 1643-1651.

[8] C. Lo Sze-Chung, K. De Verdier, R.L. Nicholson, Accumulation of 3-deoxyanthocyanidin phytoalexins and resistance to Colletotrichum sublineolum in sorghum, Physiol. Mol. Plant Pathol. 55 (1999) 263-273.

[9] W. Heller, G. Forkmann, Biosynthesis, in: J.B. Harborne (Ed.), Flavonoids: Advances in Research Since 1980, Chapman and Hall, London, 1988, pp. 399-425.

[10] W. Heller, G. Forkmann, Biosynthesis of flavonoids, in: J.B. Harborne (Ed.), Flavonoids: Advances in Research Since 1986, Chapman and Hall, London, 1994, pp. 499-535.

[11] G. Forkmann, W. Heller, Biosynthesis of flavonoids, in: D. Barton, K. Nakanishi, O. Meth-Cohn (Eds.), Comprehensive Natural Products Chemistry, Elsevier, Amsterdam, 1999, pp. $713-748$.

[12] K. Stich, G. Forkmann, Biosynthesis of 3-deoxyanthocyanins with flower extracts from Sinningia cardinalis, Phytochemistry 27 (1988) 785-789.
[13] K. Stich, G. Forkmann, Studies on Columnidin biosynthesis with flower extracts from Columnea hybrida, Z. Naturforschung 43c (1988) 311-314.

[14] W. Heller, G. Forkmann, L. Britsch, H. Grisebach, Enzymic reduction of (+)-dihydroflavonols to flavan-3,4-cis-diols with flower extracts from Matthiola incana and its role in anthocyanin biosynthesis, Planta 165 (1985) 284-287.

[15] K. Stich, T. Eidenberger, F. Wurst, G. Forkmann, Enzymatic conversion of dihydroflavonols to flavan 3,4-diols using flower extracts of Dianthus caryophyllus L. (carnation), Planta 187 (1992) $103-108$.

[16] D. Fischer, K. Stich, L. Britsch, H. Grisebach, Purification and characterization of (+)dihydroflavonol (3-hydroxyflavanone) 4reductase from flowers of Dahlia variabilis, Arch. Biochem. Biophys. 264 (1988) 40-47.

[17] R.L. Larson, Glucosylation of quercetin by a maize pollen enzyme, Phytochemistry 10 (1971) 3073-3076.

[18] R.L. Larson, C.M. Lonergan, Glucosyltransferase activity in a water extract of maize pollen, Planta 103 (1972) 361-364.

[19] R.L. Larson, E.H. Coe, Jr., Gene-dependent flavonoid glucosyltransferase in maize, Biochem. Genet. 15 (1977) 153-156.

[20] R.L. Larson, J.B. Bussard, Microsomal flavonoid 3'-monooxygenase from maize seedlings, Plant Physiol. 80 (1986) 483-486.

[21] R.L. Larson, J.B. Bussard, E.H. Coe, Jr., Gene-dependent flavonoid 3'-hydroxylation in maize, Biochem. Genet. 24 (1986) 615-624.

[22] Z. Schwarz-Sommer, N. Shephard, E. Tacke, A. Gierl, W. Rhode, L. Leclercq, M. Mattes, R. Berndtgen, P.A. Peterson, H. Saedler, Influence of transposable elements on the structure and function of the A1 gene of Zea mays, EMBO J. 6 (1987) 287-294.

[23] A.R. Reddy, L. Britsch, F. Salamini, H. Saedler, W. Rohde, The A1 (anthocyanin-1) locus in Zea mays encodes dihydroquercetin reductase, Plant Sci. 52 (1987) 7-12.

[24] E.D. Styles, O. Ceska, Pericarp flavonoids in genetic strains of Zea mays, Maydica 34 (1989) 227-237.

[25] G. Forkmann, B. Ruhnau, Distinct substrate specificity of dihydroflavonol 4-reductase from flowers of Petunia hybrida, Z. Naturforsch. 42c (1987) 1146-1148.

[26] P. Meyer, I. Heidmann, G. Forkmann, H. Saedler, A new petunia flower colour generated by transformation of a mutant with a maize gene, Nature 330 (1987) 677-678.

[27] L. Britsch, W. Heller, H. Grisebach, Conversion of flavanone to flavone, dihydroflavonol and flavonol with an enzyme system from cell cultures of parsley, Z. Naturforsch. 36c (1981) $742-750$.

[28] L. Britsch, H. Grisebach, Improved preparation and assay of chalcone synthase, Phytochemistry 24 (1985) 1975-1976.

[29] G. Stotz, P. de Vlaming, H. Wiering, A.W. Schram, G. Forkmann, Genetic and biochemical studies on the conversion of flavanones to dihydroflavonols in flowers of Petunia hybrida, Theor. Appl. Genet. 70 (1985) 561-568.

[30] H. Sandermann, L. Strominger, Purification and properties of C55-isoprenoid alcohol phosphokinase from Staphylococcus aureus, J. Biol. Chem. 247 (1972) 5123-5131.

[31] S, Martens, T. Teeri, G. Forkmann, Heterologous expression of dihydroflavonol 4-reductases from various plants, FEBS Lett. 531 (2002) $453-458$. 